\title{
Low prevalence of Human Papillomavirus in oral cavity carcinomas
}

\author{
Jerry Machado ${ }^{1,2}$, Patricia P Reis ${ }^{2}$, Tong Zhang ${ }^{2}$, Colleen Simpson ${ }^{3}$, Wei $\mathrm{Xu}^{4}$, Bayardo Perez-Ordonez ${ }^{5}$, \\ David P Goldstein ${ }^{3}$, Dale H Brown ${ }^{3}$, Ralph W Gilbert ${ }^{3}$, Patrick J Gullane', Jonathan C Irish', \\ Suzanne Kamel-Reid ${ }^{1,2,6,7^{*}}$
}

\begin{abstract}
Background: Increasing evidence shows that Human Papillomavirus (HPV) is preferentially associated with some head and neck squamous cell carcinomas (HNSCCS), with variable infection rates reported.

Methods: We assessed HPV involvement in HNSCC using the Roche Linear Array HPV Genotyping Test, which can detect 37 different HPV types. We examined the prevalence of HPV infection in 92 HNSCCs (oropharynx, oral cavity, and other HNSCC sites).

Results: HPV was frequently detected in oropharyngeal cancers (OPCs) $(16 / 22,73 \%)$, but was uncommon in oral cavity cancers $(2 / 53,4 \%)$, and in other HNSCC subsites $(1 / 17,6 \%)$. HPV positive tumors were associated with patients that were $40-60$ years old $(p=0.02)$, and node positive $(p=<0.0001)$. HPV 16 was the most prevalent type, but other types detected included 6, 18, 33, 35, 45, and 52/58.

Conclusion: Our results show that in contrast to oropharyngeal cancers, oral cancers and other HNSCCS

infrequently harbor HPV.
\end{abstract}

\section{Introduction}

In 2009, head and neck squamous cell carcinoma (HNSCC) had an estimated incidence of 48,010 cases (11,260 deaths) within the U.S. (American Cancer Society), and 4,550 cases (1,660 deaths) in Canada (Canadian Cancer Society). The most common risk factors for HNSCC development are excessive tobacco and/or alcohol consumption [1]. In addition, human papillomavirus (HPV) infection has been associated with some HNSCC subsites [2].

Most HPV research has primarily focused on cervical cancer, as $>99 \%$ of cervical cancers harbor HPV [3]. Over 130 HPV types are known; these are classified as low- or high-risk based on their association with cervical carcinoma. HPV-16 and HPV-18 are the most commonly detected high-risk types [3]. High-risk HPVs promote tumorigenesis through expression of the E6 and E7 oncoproteins, which inactivate the tumor suppressors TP53 and RB1, respectively [4]. HPV-positive tumors

\footnotetext{
* Correspondence: suzanne.kamel-reid@uhn.on.ca
'Department of Laboratory Medicine and Pathobiology, University of

* Correspondence: suzanne.kamel-reid@uhn.on.ca
${ }^{1}$ Department of Laboratory Medicine and Pathobiology, University of Toronto, Toronto, Ontario, Canada
}

feedback mechanism involving RB1 inactivation [5].

Data from the literature show widely variable HPV infection rates in HNSCC [6-10]. This variability may be attributable to: sample storage and preparation of DNA [11]; ethnicity and geography [10,12]; small number of samples analyzed [10]; possible contamination [7]; detection technique used, and HNSCC site analyzed [6,7]. In a case-controlled study of HPV infection in HNSCC, HPV-16 was present in $72 \%$ of oropharyngeal carcinomas (OPCs), and associated with specific sexual behaviors [13], and marijuana use [14]. Unlike the striking association with oropharyngeal cancers, the incidence of HPV in other head and neck sites remains unclear. Interestingly, HPV positive HNSCCs are biologically different than HPV negative tumors, as shown by distinct gene expression profiles $[15,16]$. Importantly, patients with HPV positive HNSCC have better survival due to increased sensitivity to chemoradiotherapy [11].

We examined the prevalence of HPV in oral squamous cell carcinomas (OSCCs), compared to other head and neck subsites and OPCs. For HPV detection and 
genotyping, a sensitive and specific PCR-based method, the Roche Linear Array HPV Genotyping test was used for these studies.

\section{Materials and methods Patients}

The University Health Network (UHN) Research Ethics Board approved this study; informed consent was obtained from all patients prior to sample collection. Medical records were examined to obtain detailed clinical and histopathological information, including age, sex, disease site, histopathological diagnosis, disease stage, history of tobacco and alcohol use, nodal metastasis, treatment, and outcome. Subsets of patients were classified as social or rare alcohol drinkers as written in their clinical reports. Patients having no use of tobacco or alcohol within one year prior to surgery were classified as former smokers and drinkers, respectively. Tumors were staged according to the current TNM classification, as recommended by the American Joint Committee on Cancer (UICC, 2002).

Patients over 60 years of age often present with HNSCC, whereas young patients with HNSCC are often characterized as patients under 35-45 years of age [17]. The patients examined in our study were stratified as young ( $\leq 40$ years of age), intermediate age $(>40$ and $<60$ ) or older patients ( $\geq 60$ years old). The median age was 59 (range, 22-93 years of age). The male-female ratio was approximately $2: 1$. Median follow up time was 22 months (range, 1-140 months).

\section{Tumor samples and DNA isolation}

The 92 samples used in this study were retrospectively collected between 1995-2007. 78 HNSCC samples were obtained at the time of surgery from the Toronto General Hospital. Tissues were snap frozen and stored in liquid nitrogen. Also, 14 HNSCC were formalin fixed paraffin embedded samples. H\&E stained sections were examined by histopathology (B.P-O.) to confirm $>80 \%$ tumor in the specimens being tested.

DNA was isolated following fresh frozen tissue homogenization in liquid nitrogen using a cold steel mortar and pestle. Homogenized tissue was lysed in SNET buffer (1\% SDS, $400 \mathrm{mM} \mathrm{NaCl}, 5 \mathrm{mM}$ EDTA, $20 \mathrm{mM}$ Tris, $\mathrm{pH} 8.0$ ), containing $400 \mu \mathrm{g} / \mathrm{mL}$ proteinase $\mathrm{K}$ overnight at $55^{\circ} \mathrm{C}$. After digestion, $25 \mathrm{mg} / \mathrm{mL}$ RNase was added and DNA was extracted by standard techniques using phenol/chloroform and ethanol precipitation. DNA quantity and quality was assessed by spectrophotometry (Nanodrop, Thermo Scientific, Waltham, MA) and electrophoresis on a $0.8 \%$ agarose gel. Genomic DNA was isolated from formalin fixed paraffin embedded (FFPE) samples using the DNeasy Blood and Tissue Kit (Qiagen, Valencia, CA).

\section{HPV detection}

The Roche Linear Array HPV Genotyping test (Roche Diagnostics, Branchburg, NJ) was used for the detection of 37 low- and high-risk HPV types, according to manufacturer's instructions. Briefly, it utilizes biotinylated PCR of the HPV L1 region and reverse blotting to multiple HPV genotypes. HPV types were determined by lining up the manufacturer's HPV reference guide with the genotyping strip. A low- and high-copy $\beta$-globin internal control is included in each run to assess the quality of DNA sample. All experiments included an HPV positive control, an HPV negative control, and a no-template control. Cases that were HPV positive were repeated, without the presence of a positive control, to verify results and exclude the risk of contamination.

\section{Statistical methods}

Descriptive statistics were examined as median and range for continuous variables, and frequencies and proportions for categorical variables. The Fisher's exact and Pearson's chi-square tests were used for statistical evaluation. Overall survival was calculated using the Kaplan-Meier method. A Cox Proportional Hazard regression model was applied for continuous predictors. Results were considered significant if $\mathrm{p} \leq 0.05$. Statistical analyses were performed using the SAS 9.1 software package (SAS Institute, Cary, NC).

\section{Results}

All 92 HNSCC samples had a positive $\beta$-globin internal control on the linear array and were thus suitable for HPV analysis. Of these, 53 were from sites in the oral cavity: tongue, floor of mouth (FOM), palate, buccal mucosa and gingiva; 17 were from other sites (pharynx, nasopharynx, hypopharynx and larynx); and 22 were from the oropharynx (base of tongue and tonsil). The oropharyngeal cases were selected for comparison, as these tumors have a higher incidence of HPV infection.

HPV positivity was stratified according to distinct HNSCC subsites: 2/53 (4\%) OSCCs, 16/22 (73\%) OPCs, and $1 / 17(6 \%)$ tumors from other HNSCC sites were HPV positive. HPV positivity was significantly associated with OPCs $(\mathrm{p}<0.0001)$ (Table 1$)$. The most prevalent HPV subtype found in our analysis was the high-risk HPV-16 (12/19 cases) (Figure 1), which is the most common subtype observed in HNSCC [10]. We detected lowrisk HPV-6 in one sample, and high-risk HPV types: 18 , $33,35,45$, and 52/58. 3/19 HPV positive cases, which were OPCs had confirmed multiple infections; and 1/19 HPV positive cases (Tongue SCC) had a low-level infection of HPV-18, as compared to the $\beta$-globin control.

HPV was significantly associated in node positive patients $v s$. node negative patients $(\mathrm{p}<0.0001)$ (Table $1)$. When we stratified individuals into young $(\leq 40$ 
Table 1 Statistical association of clinical factors and HPV status

\begin{tabular}{|c|c|c|c|c|}
\hline Category & Variable & Patients (\#) & $\mathrm{HPV}+(\%)$ & p-value \\
\hline \multirow[t]{3}{*}{ Age } & $<=40$ & 22 & $1(4.5)$ & 0.02 \\
\hline & $>40$ and $<60$ & 28 & $10(35.7)$ & \\
\hline & $>=60$ & 42 & $8(19)$ & \\
\hline \multirow[t]{2}{*}{ Sex } & $\mathrm{F}$ & 28 & $4(14.3)$ & 0.32 \\
\hline & M & 64 & $15(23.4)$ & \\
\hline \multirow[t]{3}{*}{ Smoking } & Y & 53 & $11(20.8)$ & 0.59 \\
\hline & $\mathrm{N}$ & 32 & $6(18.8)$ & \\
\hline & Former & 5 & $0(0)$ & \\
\hline \multirow[t]{4}{*}{ Alcohol } & Y & 46 & 9 (19.6) & 0.47 \\
\hline & $\mathrm{N}$ & 19 & $2(10.5)$ & \\
\hline & Former & 6 & $0(0)$ & \\
\hline & Other & 18 & $5(27.8)$ & \\
\hline \multirow[t]{4}{*}{ Stage } & । & 6 & $0(0)$ & 0.12 \\
\hline & $\|$ & 22 & $1(4.5)$ & \\
\hline & III & 21 & $5(23.8)$ & \\
\hline & IV & 40 & $10(25)$ & \\
\hline \multirow[t]{4}{*}{ Tumor Differentiation } & Well & 1 & $0(0)$ & 0.51 \\
\hline & Moderately & 68 & $12(17.6)$ & \\
\hline & Poorly & 18 & $5(27.8)$ & \\
\hline & Other & 5 & $2(40)$ & \\
\hline \multirow[t]{6}{*}{ Site } & Tongue & 29 & $1(3.4)$ & $<0.0001$ \\
\hline & FOM & 8 & $1(12.5)$ & \\
\hline & FOM+Tongue & 6 & $0(0)$ & \\
\hline & Oropharynx (Base of Tongue) & 22 & $16(72.7)$ & \\
\hline & Larynx/Pharynx/Nasopharynx & 17 & $1(5.9)$ & \\
\hline & Other & 10 & $0(0)$ & \\
\hline \multirow[t]{2}{*}{ Node } & + & 43 & $15(34.9)$ & $<0.0001$ \\
\hline & - & 46 & $1(2.2)$ & \\
\hline \multirow[t]{2}{*}{ Outcome } & Alive & 83 & $17(20.5)$ & 0.24 \\
\hline & Dead & 7 & $0(0)$ & \\
\hline \multirow[t]{2}{*}{ HPV } & + & 19 & & \\
\hline & - & 73 & & \\
\hline
\end{tabular}

Clinical categories and the variables were examined for significant associations with HPV status. Statistical significance was assessed by Fisher's exact and Pearson's chi-square tests ( $\mathrm{p} \leq 0.05)$. M - Male; F - Female; $Y$ - Yes; N - No; FOM - Floor of Mouth. Unknown values were not included in analysis.

years old), intermediate age ( $>40$ and $<60$ years old), and older ( $\geq 60$ years old) HNSCC patients, HPV positive tumors were associated with the intermediate age patient group $(\mathrm{p}=0.02)$. There were no significant associations between HPV and smoking or alcohol status. We also found no association between HPV infection and tumor differentiation and stage. In other studies, these associations have been inconsistent [6].
Survival was not significantly different for HPV-positive $v$ s. HPV-negative HNSCCs $(\mathrm{p}=0.24)$ (Table 1), as non-OPC sites were mainly HPV negative. Further examination of the 22 patients with OPC showed that outcomes for patients with HPV positive tumors included: $1 / 16$ patients was alive with disease, 14/16 patients were alive with no evidence of disease, and 1/16 had lost to follow up. In contrast, $3 / 6$ patients with HPV 


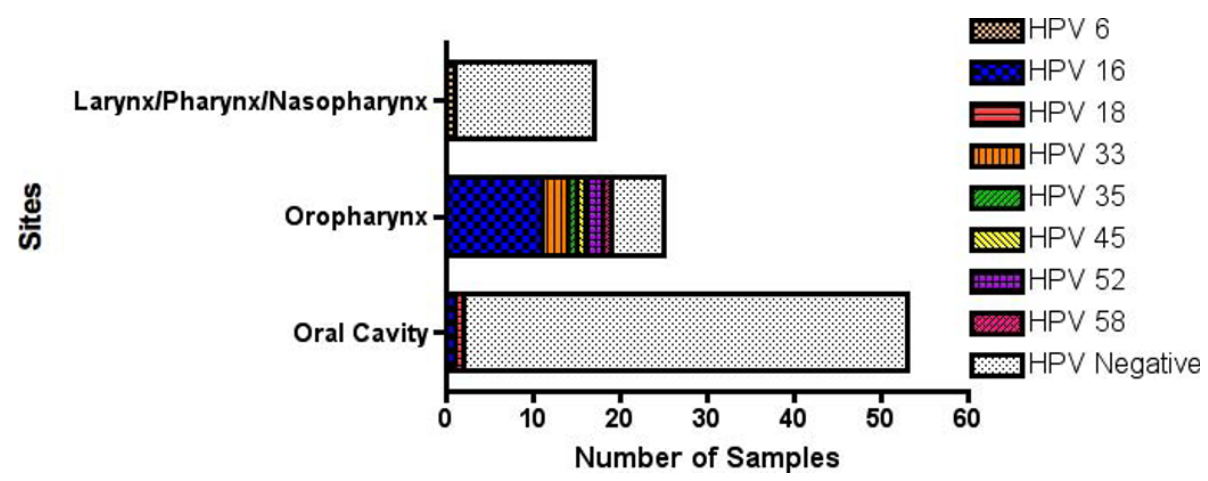

Figure 1 Head and neck cancer sites and detected HPV types. HPV types were highly associated with the oropharynx and rarely detected in oral cavity cancers and other head and neck cancer sites.

negative tumors were alive with disease, $2 / 6$ patients were alive with no evidence of disease and $1 / 6$ patients died of disease. Regardless of HPV status, we observed a significant gender-based difference in overall survival. Of the 7 deceased patients, 5 were females, non-smokers and non-drinkers; 3 of these were young and 2 were older patients; all of these patients were HPV negative. It has been suggested that a subgroup of young nonsmoking female patients may have an aggressive form of HNSCC [18], although this would have to be tested in a larger cohort of patients.

\section{Discussion}

In our study, we sought to determine HPV infection rates in OSCC, in comparison to other HNSCC sites such as OPC. We observed significant differences in HPV positivity among different HNSCC sites, with OPCs having the highest infection rate. We also detected a low infection rate within OSCC samples. In the literature, most HPV studies do not provide stratification between oral cavity subsites, e.g. mobile tongue $v s$. base of tongue; the latter is associated with a higher HPV prevalence due to the involvement of the oropharynx [11]. Indeed, high HPV prevalence has been consistently shown in OPC compared to a lower prevalence in other HNSCCs [19]. A recent comprehensive examination of the Surveillance, Epidemiology and End Results (SEER) database showed a significant increase in HPVrelated vs. HPV-unrelated OPCs from 1973-2004 [20]. In this SEER analysis, HPV-related HNSCCs mainly involved the oropharynx (base of tongue, and palatine tonsils), whereas HPV-unrelated HNSCCs were from the mobile tongue, floor of mouth and palate. Gillison et al. used in situ hybridization for HPV detection and showed a higher frequency of HPV in tumors of the oropharynx, low frequency in larynx and oral cavity, and an absence of HPV in the hypopharynx or nasopharynx [14].
In our study, we observed a significant association of HPV positive tumors to be present in HNSCCs from intermediate age patients. It has been suggested that, from the time of sexual transmission of HPV, a clinical lesion can appear within two decades, in contrast to conventional risk factors (tobacco smoking and alcohol consumption), which may take several decades [21].

Interestingly, HPV positive HNSCCS have also been associated with lymph node metastasis. For example, in another study, HPV positive salivary samples were correlated with node-positive patients, suggesting that HPV infection may result from a cellular immunological deficiency that impedes the cancer cell's ability to clear HPV and thus result in cancer development, recurrence and metastasis [22]. Among patients with lymph node metastasis, HPV positive patients have a better prognosis than HPV negative patients, due to a better response to radiotherapy [23]. We did not detect significant differences in survival for patients with HPV positive $v s$. negative tumors, as most OSCCs were HPV negative in our study, and possibly due to the relative small sample size of OPCs analyzed.

Some studies have shown a higher prevalence of HPV in OSCCs and other head and neck sites outside the oropharynx. For example, examination of HPV status in OSCC from 50 Brazilian patients (excluding OPC), showed 24\% HPV positivity, mostly HPV-16/18 [24]. In a Mexican patient cohort, a high frequency of HPV positivity (43.5\%) was found in OSCC [25]. Such differences may be attributable to different HPV susceptibilities in different ethnicities/geographic regions or they may be due to different HPV detection methods. Boy et al. detected 7/59 (12\%) HPV-18 positivity in oral cancer using quantitative real-time PCR and $0 \%$ positivity when using in situ hybridization assays on the same samples [26]. Our data have added to the literature by using a sensitive and comprehensive HPV detection and genotyping assay in HNSCC. This assay is currently used as 
a standardized diagnostic test for HPV detection and genotyping in cervical carcinomas in Europe [27]. In our study, by using this robust HPV detection and genotyping method, we showed that HPV is rarely involved in oral carcinomas and other non-OPC head and neck sites.

\section{Acknowledgements}

The authors would like to acknowledge their sources of support: Canadian Cancer Society (Grant \# 016289) and the Wharton Head and Neck Fund. We thank Dr. Mahadeo A. Sukhai, PhD, for his helpful critique and editorial review of the manuscript.

\section{Author details}

${ }^{1}$ Department of Laboratory Medicine and Pathobiology, University of Toronto, Toronto, Ontario, Canada. ²Division of Applied Molecular Oncology, Princess Margaret Hospital, Ontario Cancer Institute and University Health Network, Toronto, Ontario, Canada. ${ }^{3}$ Department of Otolaryngology/Surgical Oncology, Princess Margaret Hospital, Ontario Cancer Institute and University Health Network, Toronto, Ontario, Canada. ${ }^{4}$ Department of Biostatistics, Princess Margaret Hospital, University Health Network, Toronto, Ontario, Canada. ${ }^{5}$ Department of Pathology, Toronto General Hospital, University Health Network, Toronto, Ontario, Canada. ${ }^{6}$ Institute for Medical Sciences, University of Toronto, Toronto, Ontario, Canada. ${ }^{7}$ Department of Medical Biophysics, University of Toronto, Toronto, Ontario, Canada.

\section{Authors' contributions}

JM was responsible for study design and content, literature research, experimental studies, data analysis, and manuscript preparation. PPR was involved in study design, data analysis, manuscript editing and review. TZ performed experimental studies. CS was responsible for data acquistion, and study concepts. WX perfomed the statistical analysis. BPO was involved with the data analysis. DPG, DHB, RWG, PJG, JCl were involved in study concepts, and sample acquistion. SKR was responsible for study content and design, manuscript editing and review.

All authors have read and approved the final manuscript.

\section{Competing interests}

The authors declare that they have no competing interests.

Received: 14 January 2010 Accepted: 12 March 2010

Published: 12 March 2010

\section{References}

1. Hashibe M, Brennan P, Benhamou S, Castellsague X, Chen C, Curado MP, Dal Maso L, Daudt AW, Fabianova E, Fernandez L, Wunsch-Filho V, Franceschi S, Hayes RB, Herrero R, Koifman S, La Vecchia C, Lazarus P, Levi F, Mates D, Matos E, Menezes A, Muscat J, Eluf-Neto J, Olshan AF, Rudnai P, Schwartz SM, Smith E, Sturgis EM, Szeszenia-Dabrowska N, Talamini R, Wei Q, Winn DM, Zaridze D, Zatonski W, Zhang ZF, Berthiller J, Boffetta P: Alcohol drinking in never users of tobacco, cigarette smoking in never drinkers, and the risk of head and neck cancer: pooled analysis in the International Head and Neck Cancer Epidemiology Consortium. J Natl Cancer Inst 2007, 99:777-789.

2. Fakhry C, Gillison ML: Clinical implications of human papillomavirus in head and neck cancers. J Clin Oncol 2006, 24:2606-2611.

3. Walboomers JM, Jacobs MV, Manos MM, Bosch FX, Kummer JA, Shah KV, Snijders PJ, Peto J, Meijer CJ, Munoz N: Human papillomavirus is a necessary cause of invasive cervical cancer worldwide. J Pathol 1999, 189:12-19.

4. Nair S, Pillai MR: Human papillomavirus and disease mechanisms: relevance to oral and cervical cancers. Oral Dis 2005, 11:350-359.

5. Hafkamp HC, Speel EJ, Haesevoets A, Bot FJ, Dinjens WN, Ramaekers FC, Hopman AH, Manni JJ: A subset of head and neck squamous cell carcinomas exhibits integration of HPV 16/18 DNA and overexpression of p16INK4A and p53 in the absence of mutations in p53 exons 5-8. Int J Cancer 2003, 107:394-400.
6. Campisi G, Panzarella V, Giuliani M, Lajolo C, Di Fede O, Falaschini S, Di Liberto C, Scully C, Lo Muzio L: Human papillomavirus: its identity and controversial role in oral oncogenesis, premalignant and malignant lesions (review). Int J Oncol 2007, 30:813-823.

7. Ha PK, Califano JA: The role of human papillomavirus in oral carcinogenesis. Crit Rev Oral Biol Med 2004, 15:188-196.

8. Herrero R, Castellsague X, Pawlita M, Lissowska J, Kee F, Balaram P, Rajkumar T, Sridhar H, Rose B, Pintos J, Fernandez L, Idris A, Sanchez MJ, Nieto A, Talamini R, Tavani A, Bosch FX, Reidel U, Snijders PJ, Meijer CJ, Viscidi R, Munoz N, Franceschi S: Human papillomavirus and oral cancer: the International Agency for Research on Cancer multicenter study. J Natl Cancer Inst 2003, 95:1772-1783.

9. Hobbs CG, Sterne JA, Bailey M, Heyderman RS, Birchall MA, Thomas SJ: Human papillomavirus and head and neck cancer: a systematic review and meta-analysis. Clin Otolaryngol 2006, 31:259-266.

10. Kreimer AR, Clifford GM, Boyle P, Franceschi S: Human papillomavirus types in head and neck squamous cell carcinomas worldwide: a systematic review. Cancer Epidemiol Biomarkers Prev 2005, 14:467-475.

11. Dahlgren L, Dahlstrand HM, Lindquist D, Hogmo A, Bjornestal L, Lindholm J, Lundberg B, Dalianis T, Munck-Wikland E: Human papillomavirus is more common in base of tongue than in mobile tongue cancer and is a favorable prognostic factor in base of tongue cancer patients. Int $\mathrm{J}$ Cancer 2004, 112:1015-1019.

12. Li W, Tran N, Lee SC, O'Brien CJ, Tse GM, Scolyer RA, Hong A, Milross C, $\mathrm{Yu} \mathrm{KH}$, Rose BR: New evidence for geographic variation in the role of human papillomavirus in tonsillar carcinogenesis. Pathology (Phila) 2007, 39:217-222.

13. D'Souza G, Kreimer AR, Viscidi R, Pawlita M, Fakhry C, Koch WM, Westra WH, Gillison ML: Case-control study of human papillomavirus and oropharyngeal cancer. N Engl J Med 2007, 356:1944-1956.

14. Gillison ML, D'Souza G, Westra W, Sugar E, Xiao W, Begum S, Viscidi R: Distinct risk factor profiles for human papillomavirus type 16-positive and human papillomavirus type 16-negative head and neck cancers. J Natl Cancer Inst 2008, 100:407-420.

15. Schlecht NF, Burk RD, Adrien L, Dunne A, Kawachi N, Sarta C, Chen Q, Brandwein-Gensler M, Prystowsky MB, Childs G, Smith RV, Belbin TJ: Gene expression profiles in HPV-infected head and neck cancer. J Pathol 2007, 213:283-293.

16. Slebos RJ, Yi Y, Ely K, Carter J, Evjen A, Zhang X, Shyr Y, Murphy BM Cmelak AJ, Burkey BB, Netterville $J$, Levy $S$, Yarbrough WG, Chung $\mathrm{CH}$ : Gene expression differences associated with human papillomavirus status in head and neck squamous cell carcinoma. Clin Cancer Res 2006, 12:701-709.

17. Goldstein DP, Irish JC: Head and neck squamous cell carcinoma in the young patient. Curr Opin Otolaryngol Head Neck Surg 2005, 13:207-211.

18. Funk GF, Karnell LH, Robinson RA, Zhen WK, Trask DK, Hoffman HT: Presentation, treatment, and outcome of oral cavity cancer: a National Cancer Data Base report. Head Neck 2002, 24:165-180.

19. Ringstrom E, Peters E, Hasegawa M, Posner M, Liu M, Kelsey KT: Human papillomavirus type 16 and squamous cell carcinoma of the head and neck. Clin Cancer Res 2002, 8:3187-3192.

20. Chaturvedi AK, Engels EA, Anderson WF, Gillison ML: Incidence trends for human papillomavirus-related and -unrelated oral squamous cell carcinomas in the United States. J Clin Oncol 2008, 26:612-619.

21. El-Mofty SK, Lu DW: Prevalence of human papillomavirus type 16 DNA in squamous cell carcinoma of the palatine tonsil, and not the oral cavity, in young patients: a distinct clinicopathologic and molecular disease entity. Am J Surg Pathol 2003, 27:1463-1470.

22. Chuang AY, Chuang TC, Chang S, Zhou S, Begum S, Westra WH, Ha PK, Koch WM, Califano JA: Presence of HPV DNA in convalescent salivary rinses is an adverse prognostic marker in head and neck squamous cell carcinoma. Oral Oncol 2008.

23. Hoffmann M, Gorogh T, Gottschlich S, Lohrey C, Rittgen W, Ambrosch P, Schwarz E, Kahn T: Human papillomaviruses in head and neck cancer: 8 year-survival-analysis of 73 patients. Cancer Lett 2005, 218:199-206.

24. Acay R, Rezende N, Fontes A, Aburad A, Nunes F, Sousa S: Human papillomavirus as a risk factor in oral carcinogenesis: a study using in situ hybridization with signal amplification. Oral Microbiol Immunol 2008, 23:271-274.

25. Anaya-Saavedra G, Ramirez-Amador V, Irigoyen-Camacho ME, GarciaCuellar CM, Guido-Jimenez M, Mendez-Martinez R, Garcia-Carranca A: High 
association of human papillomavirus infection with oral cancer: a casecontrol study. Arch Med Res 2008, 39:189-197.

26. Boy S, Van Rensburg EJ, Engelbrecht S, Dreyer L, van Heerden M, van Heerden W: HPV detection in primary intra-oral squamous cell carcinomas-commensal, aetiological agent or contamination? J Oral Pathol Med 2006, 35:86-90.

27. Dunn ST, Allen RA, Wang S, Walker J, Schiffman M: DNA extraction: an understudied and important aspect of HPV genotyping using PCR-based methods. J Virol Methods 2007, 143:45-54.

doi:10.1186/1758-3284-2-6

Cite this article as: Machado et al:: Low prevalence of Human

Papillomavirus in oral cavity carcinomas. Head \& Neck Oncology 2010 2:6.

Submit your next manuscript to BioMed Central and take full advantage of:

- Convenient online submission

- Thorough peer review

- No space constraints or color figure charges

- Immediate publication on acceptance

- Inclusion in PubMed, CAS, Scopus and Google Scholar

- Research which is freely available for redistribution

Submit your manuscript at www.biomedcentral.com/submit 